\title{
Clip-anchoring technique: a fast, cheap, and efficient way to close a gastric peroral endoscopic pyloromyotomy tunnel
}

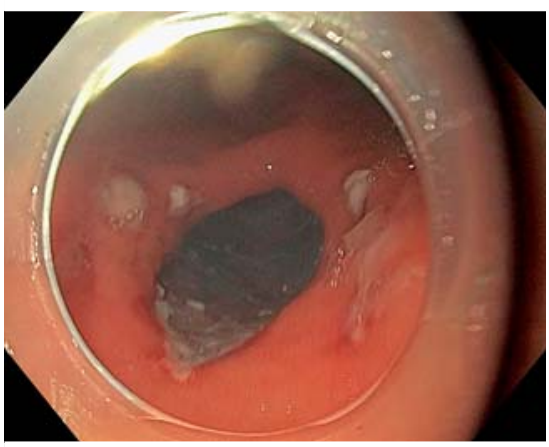

- Fig. 1 Incisions for clip placement made at the beginning of the procedure.

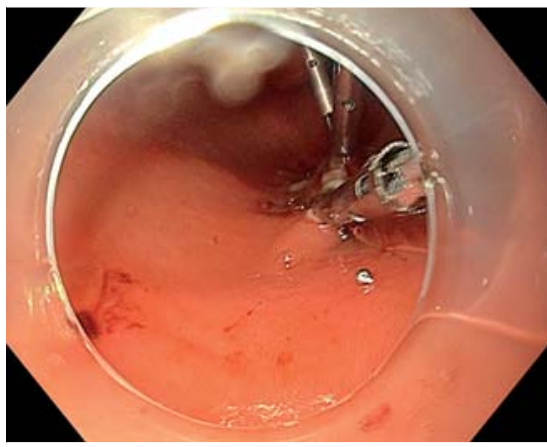

Fig. 4 Full closure of tunnel with three clips.

Gastric peroral endoscopic pyloromyotomy (G-POEM) is a treatment option for refractory gastroparesis [1]. The technique is similar to the esophageal peroral endoscopic myotomy [2]. However, tunnel closure may be difficult because of the gastric mucosa stretching at the end of the procedure.

We report here the case of a 38-year-old woman suffering from severe diabetic gastroparesis. She had already undergone unsuccessful pyloric botulinum toxin injections. The gastric emptying time was 146 minutes at preoperative scintigraphy.

We decided to perform a G-POEM ( $\vee$ Video 1). After the submucosal injection, a $1-\mathrm{cm}$ incision was made using an Endocut I effect 2 current, $5 \mathrm{~cm}$ above

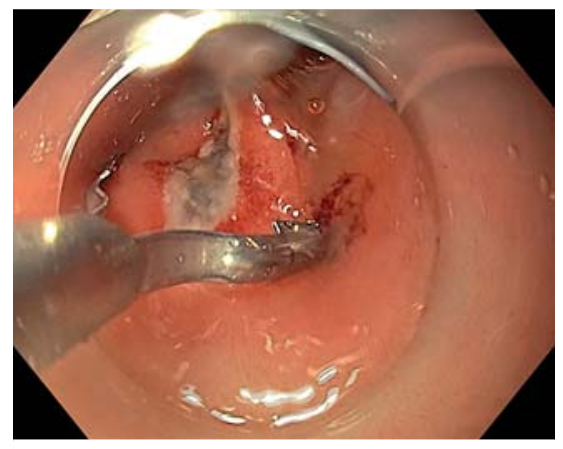

- Fig. 2 Incisions used to anchor a clip.

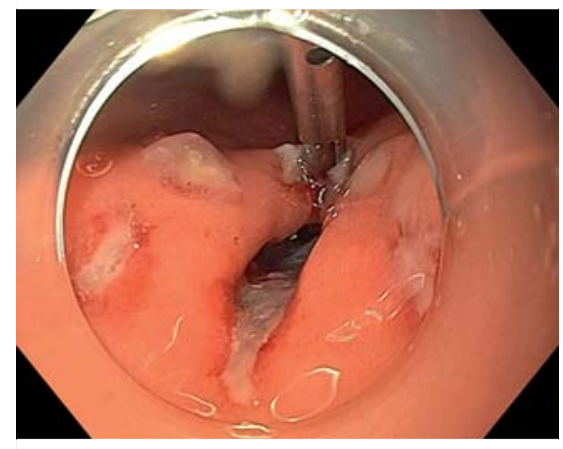

- Fig. 3 Clip in position.

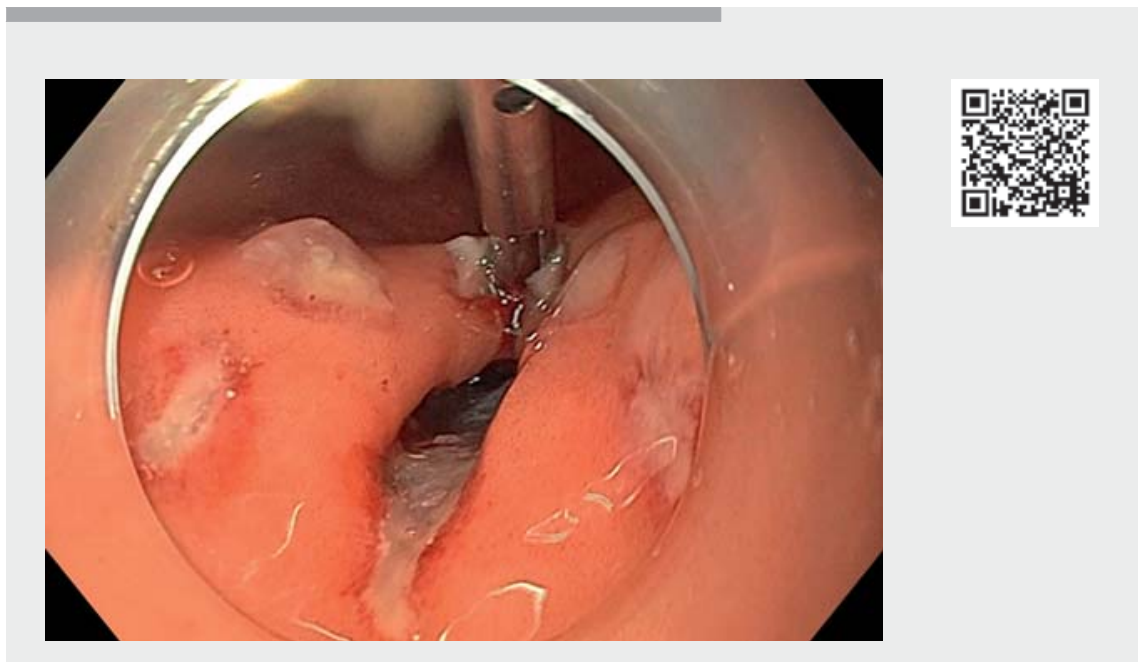

Video 1 Gastric peroral endoscopic pyloromyotomy with clip-anchoring technique to ease the tunnel closure.

the pylorus. Immediately after, the same current was used to make three small incisions on each side of the tunnel entrance ( $\triangleright$ Fig. 1 ) to allow clip anchoring at the end of the procedure. The rest of the procedure was a standard G-POEM: after the submucosal trimming inside the tunnel to the pyloric arch, a deep pyloromyotomy was made. The previously made incisions were used to place three clips to ease the tunnel closure (clip anchoring technique, > Fig. 2, > Fig. 3 , - Fig.4). The overall procedure lasted 25 minutes and the tunnel closing lasted
3 minutes. There were no complications after the procedure, except an early dumping syndrome the day after the procedure, which is a common adverse event after a G-POEM [3].

To our knowledge, this is the first ever case report showing the clip-anchoring technique to close a G-POEM tunnel. This technique is effective and easy. It is also cheaper than the use of over-thescope clips recently described [4].

Endoscopy_UCTN_Code_TTT_1AO_2AN 


\section{Competing interests}

The authors declare that they have no conflict of interest.

The authors

Lucile Héroin ${ }^{\circledR}$, Mathieu Pioche², Pierre Lafeuille $^{2}$, Jérémie Jacques ${ }^{3}$, Martin Bordet ${ }^{4}$, Pierre Mayer $^{1}{ }^{\oplus}$, Thomas Lambin ${ }^{2}$

1 Gastroenterology and Hepatology Unit, Hôpitaux Universitaires de Strasbourg, Strasbourg, France

2 Department of Endoscopy and HepatoGastroenterology, Pavillon L, Edouard Herriot Hospital, Lyon, France

3 Gastroenterology and Endoscopy Unit, Dupuytren University Hospital, Limoges, France

4 Department of Gastroenterology, University Hospital of Rennes, Pontchaillou, Rennes, France

\section{Lucile Héroin, MD}

Gastroenterology and Hepatology Unit, Hôpitaux Universitaires de Strasbourg,

1 quai Louis Pasteur, 67000 Strasbourg, France

lucileheroin@gmail.com

\section{References}

[1] Gonzalez J-M, Lestelle V, Benezech A et al. Gastric per-oral endoscopic myotomy with antropyloromyotomy in the treatment of refractory gastroparesis: clinical experience with follow-up and scintigraphic evaluation (with video). Gastrointest Endosc 2017; 85: 132-139

[2] Inoue H, Minami H, Kobayashi Y et al. Peroral endoscopic myotomy (POEM) for esophageal achalasia. Endoscopy 2010; 42: 265271

[3] Louazon T, Rivory J, Roman S et al. Temporary dumping syndrome after gastric peroral endoscopic myotomy: should we control the glycemia? Endoscopy 2016; 48: E10-E11

[4] Hernández Mondragón ÓV, Gutiérrez-Aguilar R, García Contreras LF et al. Conventional clips vs over-the-scope-clips for the closure of the entry site in POEM and G-POEM procedures. Rev Espanola Enfermedades Dig Organo Of Soc Espanola Patol Dig 2020; 112: 338-342
Bibliography

Endoscopy 2022; 54: E590-E591

DOI 10.1055/a-1706-0574

ISSN 0013-726X

published online 21.12.2021

(c) 2021. Thieme. All rights reserved.

Georg Thieme Verlag KG, Rüdigerstraße 14,

70469 Stuttgart, Germany

\section{ENDOSCOPY E-VIDEOS}

https://eref.thieme.de/e-videos

回题回 Endoscopy E-Videos is an open access online section, 靣: reporting on interesting cases and new techniques in gastroenterological endoscopy. All papers include a high quality video and all contributions are freely accessible online. Processing charges apply (currently EUR 375), discounts and wavers acc. to HINARI are available.

This section has its own submission website at https://mc.manuscriptcentral.com/e-videos 